\title{
Review of improvements on heat transfer using nanofluids via corrugated facing step
}

\author{
Ali Hilo ${ }^{1}$, Abd Rahim Abu Talib ${ }^{1,2^{*}}$, Sadeq R. Nfawa ${ }^{1}$, Mohamed Thariq Hameed Sultan ${ }^{2}$, \\ Mohd Faisal Abdul Hamid ${ }^{1}$ \\ ${ }^{1}$ Aerodynamic, Heat Transfer \& Propulsion Group, Department of Aerospace Engineering, \\ Universiti Putra Malaysia, 43400 Serdang, Selangor, Malaysia. \\ ${ }^{2}$ Aerospace Malaysia Research Centre, Faculty of Engineering, Universiti Putra Malaysia, 43400 Serdang, Selangor, Malaysia \\ *Corresponding author E-mail: abdrahim@upm.edu.my
}

\begin{abstract}
Nanofluids are considered to offer significant advantages as thermodynamic fluids because of their admirable properties on thermal conduction, thermal convection, boiling heat transfer and stability. This paper presents numerous researches focusing on the improvement of heat transfer via facing step and corrugated channels using nanofluids and without it. Exploration on the convective heat transfer was done through numerical modeling. It was reported that experimental studies were carried out in corrugated and facing step channels through the application of nanofluids and conventional fluids for heat transfer enhancement. The turbulent and laminar flows along corrugated and facing step channels have been presented. The numerical and experimental findings in maximizing the heat transfer rate are in accord. Comparisons between thermal conductivity measurement methods were done. Innovative design of corrugated facing step channel is being proposed. The heat transfer enhancements reach $60 \%$ by using facing step channel under laminar flow with nanofluid. The dimensions of new channel such as height and width of the baffle, the height of the step, shape and height of corrugated are needed to compare that might to provide the ideal rate of heat transfer.
\end{abstract}

Keywords: nanofluid; thermal conductivity; enhancement; corrugated; facing step.

\section{Introduction}

The flow separation and succeeding reattachment phenomena that happen as a result of sudden compression or extension in the flow passage, for instance, forward-facing (fwf) and backward-facing (bwf) steps are considered as important industrial situations. The forward- and backward-facing steps as in Figure 1 play significant part in the design of many engineering applications wherever there is a need for cooling or heating. These heat transmission applications occur in combustion chambers, cooling system for electronic devices, chemical procedures and energy systems equipment, high performance heat exchanger, cooling passages in the turbine blade and environmental control systems. Practically, the pressure drop and heat transfer augmentation in reattaching flow area and inside the reverse flow area is very large. For instance, there is low pressure drop and an improvement on the heat transfer rate attained near the wall channel region, while the heat transfer rate is low at the corner, in which the abrupt change has developed in the flow region.

Besides that, Figure 2 illustrates the corrugated channels (CC) that are utilised in numerous uses to improve heat transfer. In channels, the enhancement of heat transfer relies upon the bulk fluid mixing and re-initiation of the thermal boundary layer [1]. However, the current researches present plenty of significant experimental and numerical results regarding nanofluids, flow and heat transmission features of laminar and turbulent flow over different geometry, for example, the backward- and forward-facing steps, flat channel and corrugated channel.

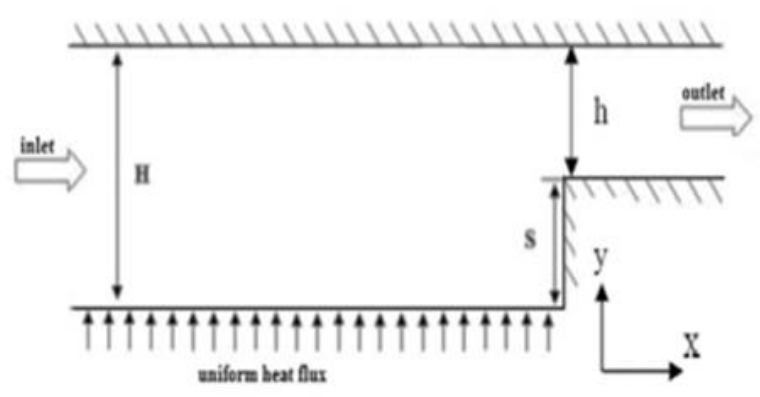

(a) Forward

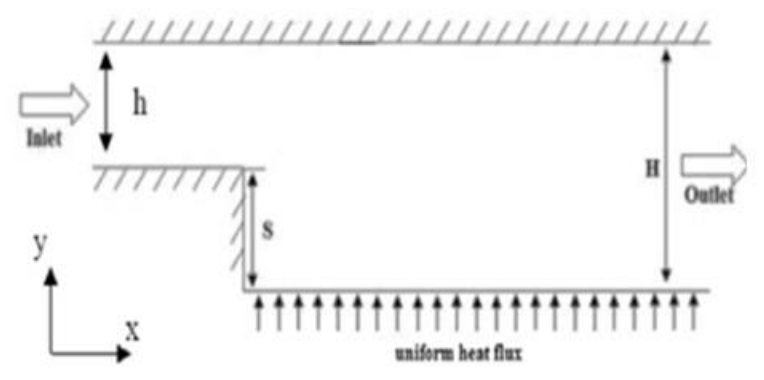

(b) Backward

Fig. 1: Facing step channel [2] 


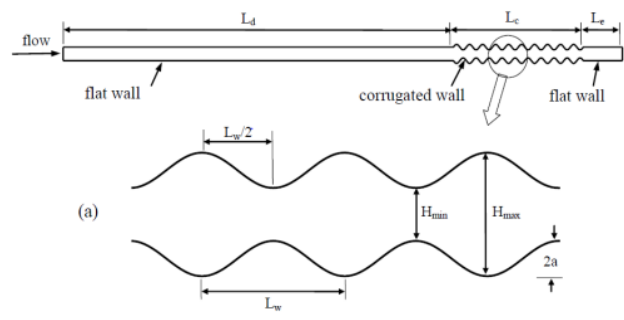

Fig. 2: Corrugated channel [1]

Based on authors' knowledge, the studies and investigations concerning the fluid flow over corrugated and facing step channels still require considerable effort since it is not entirely understood. This study intends to present an inclusive review of heat transmission augmentation through facing step and corrugated channels This paper also provides an innovative kind of nanofluids and flow in corrugated facing step channels for forthcoming studies.

\section{Heat transfer through corrugated channel}

Past studies have been done on the numerical and experimental of the convection heat transmission for conventional fluid by means of corrugate channel over the turbulent and laminar flow regions.

\subsection{Laminar flow}

In the past century, many research and experimental studies have been done on laminar flow condition for convective heat transfer of the conventional fluid in CC [3]. Typically, one of the complex channels is $\mathrm{CC}$, whereby it can provide a higher compactness as well as enhance the thermal performance [4-7]. Rush et al. [8] had carried out the heat transfer and characteristics experiment under sinusoidal wavy laminar flow via channel. The flow field visualization methods were analyzed through the use of a water tunnel whereas the conduction of heat transfer experiments within the Reynolds number $(R e)$ range of 100 to 1000 was done using wind tunnel. It is discovered that $R e$ and geometry of the channel have direct influence on the position of the mixing onset. Heat transmission was enhanced considerably by macroscopic mixing onset. Fabbri [9] studied the heat transfer via the corrugated and smooth channels at laminar flow condition. The walls of the corrugated and smooth channels have sustained uniform and adiabatic thermal flux. The finite element model was employed to find the temperature and velocity profile. The increment of Reynolds $(R e)$ and Prandtl $(P r)$ numbers were in line with the increase of heat transfer of the greatest corrugated shape, as demonstrated by the results. Moreover, $\mathrm{CC}$ with ideal geometry is capable of offering as high as 30\% improvement in heat transfer for smooth channel while the resultant penalty increment of pressure drop would only be $10 \%$.

Bahaidarah et al. [10] carried out the flow phenomena and heat transmission numerically in wavy channel over $P r=0.7$ and $R e$ range of 25 to 400 . Arc-shaped and sinusoidal configurations were studied for different geometry parameters. Finite element method (FEM) was adopted on solving the mass, momentum and energy equations. Moreover, implementation of a body-fitted grid system was done to create the grid for computational domain. To study the pressure field, the SIMPLE algorithm was applied in solving the set of discretized equations, iteratively. It was seen that the streamline contours were symmetric but the recirculation zone size increased with $R e$. The heat transmission augmentation enhanced with the increment of $R e$ for channels configuration. The sinusoidal channel experienced a scaled-down pressure drop when compared to the pressure drop in arc-shaped channel. Wang and Chen [11] hypothetically investigated the heat transmission via a sinusoidal-wavy channel over $R e$ of 100-700. The utilization of simple coordinating transformation in the governing equations has transformed the Cartesian coordinate to curvilinear coordinate. Furthermore, there was a minor augmentation of the heat transmission at lesser volume of amplitude-wavelength ratio whereas at higher value of amplitude-wavelength ratio. An admirable augmentation in the heat transfer for greater $R e$ was detected.

Mohamed et al. [12] studied the laminar convection via entrance section of a sinusoidal-wavy channel by means of numerical method. The temperature of wavy channel walls was kept constant A finite element technique was adopted in solving the 2D governing transport equations. Under the range of $R e$ of $100-1500$, the data collected were in the range of $0-0.5$ for the amplitude of wavy channel and 0.708-6.69 for $P r$. It was found that there were increment in the friction factor and heat transfer coefficient with the increasing of $R e$.

\subsection{Turbulent flow}

Many researchers have studied the convective heat transfer under turbulent flow conditions over corrugated channels [13,14]. Zhang and Che [15] studied numerical study of the effect of corrugation shape of corrugated plates on thermal hydraulic performance with air as working fluid. The governing equations of momentum, mass and energy in addition to the Lam-Bremhorst low Re turbulence model were investigated through the finite volume method. CFD analysis was conducted through the use of commercial software such as CAMBIT/FLUENT. The result shows that the heat transfer coefficient and the pressure drop were greater with sharp corrugation than that with smooth corrugation. It is found that the trapezoidal corrugated channel's friction factor and average Nusselt number $(\mathrm{Nu})$ were approximately 1 to 4 times higher than that of the elliptic CC.

For further enhancement on heat transmission in cross-corrugate triangular channels, delta-shaped baffles are added by Zhenxing and Yangyan [16]. Figure 3 illustrates the geometrical and schematic parameters of this channel structure. Numerical studies were done on the heat transfer and 3D turbulent flow in the channel. To determine the turbulent flow in $R e$ ranging from 1000 to 6000, a standard $k-\varepsilon$ turbulence model with improved wall treatment is utilized. The effects of $R e$, apex angle and baffle height on heat transmission and pressure drop were investigated. To achieve the objective of the study, field synergy principle was utilized to investigate heat transmission augmentation in flow channels with and without baffles. It was found that once inserts; clockwise vortices and anticlockwise vortices are created, respectively, in the backward region and the low corrugations of the baffles. It was also observed that once the baffle height is equal to corrugation height, the friction factor is no longer related to $R e$ in the channel with $90^{\circ}$ and $60^{\circ}$ apex angles, and will lead to an increase of $\mathrm{Nu}$ by 2.1 to 4.3 times. However, as a consequence, there will be a significant pressure loss. Furthermore, flow channel at $60^{\circ}$ apex angle operates optimum in heat transmission if the baffle height is equivalent to corrugation height, however in further studies, apex angle of $90^{\circ}$ performed better.

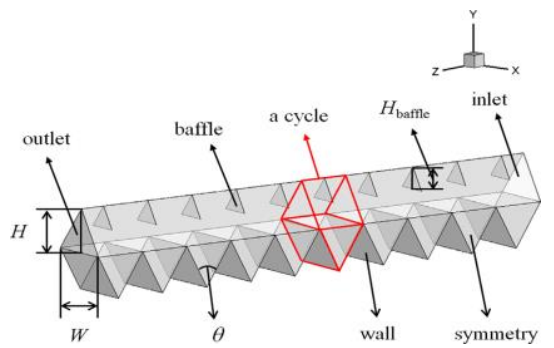

Fig. 3: Schematic of a cross-corrugated triangular channel with deltashaped baffles [16]

Oyakawa et al. [17] performed experimentally the effect of channel height on the pressure drop and heat transmission augmentation in a sinusoidal-wavy channel over the range of $R e$ of 400 to 200,000 . The amplitude and wave length of wavy channel were 20 and $80 \mathrm{~mm}$, respectively. The result predicts that once the ratio of wave length to channel height was two, the optimum performance of the wave channel could be reached. Moreover, it was noticed 
that the separation point of the flow is very reliant on the channel height whilst the reattachment point of the flow remained independent. Naphon [1] performed numerical study on heat transmission and flow improvements in the $\mathrm{CC}$ with continuous heat flux conditions. The height channel of $12.5 \mathrm{~mm}$ with three distinctive corrugated are tile angles $60^{\circ}, 40^{\circ}$ and $20^{\circ}$ are tested. $k-\varepsilon$ standard turbulent model has been used to simulate the heat transmission and flow developments. The model was simulated for heat flux and $R e$ in the range of 0.5 to $1.2 \mathrm{~kW} / \mathrm{m}^{2}$ and 400 to 1600 , respectively. The structure uniform grid system with a finite volume method was utilized to work out on the model. The expected findings then are validated through comparison with the measured data. According to the comparison, there is reasonable agreement between the experimental and the numerical data. The corrugated surface highly influences the augmentation of pressure drop and heat transmission due to destabilizing and breaking in the thermal boundary zone.

From the literatures, there is no study done using the corrugated facing step duct with baffle. Although there are several methods to enhance the heat transfer, baffle is one of the heat transfer cooling system enhancement methods and it has been applied in various applications.

\section{Heat transfer through facing step geometry}

The downstream of the step has established the separation zone within the bwf. Furthermore, fwf, flow geometry and flow field, which involved at least one separated region, could result in one downstream and the other upstream from the step. Consequently, it would be dependent on the ratio of boundary layer approaching flow to forward-facing step height at the step. The literatures surveyed show that there have been numerous studies conducted on bwf step heat transfer phenomena establishing an impact upon the fluid flow behaviour. Sparrow and Chuck [18] and Aung [19] were among the first investigators to report and establish numerical and also experimental findings on the heat transmission for $2 \mathrm{D}$ laminar-transient flow with air as working liquid. They utilized a bwf step channel that was heated at constant temperature from below. The findings revealed that $N u$ was not dependent of $R e$ and that the distribution of the local $N u$ starts with an appropriate value at the step. It attains the highest value when it is positioned close to the reattachment point and reduces steadily to the completely developed value.

Various studies investigated the influence of the heat transmission and flow on 3D backward-facing step ducts using several parameters by Iwai et al. [20,21]. Various researchers [20,22-24] have numerically simulated a low $R e$ three-dimensional mixed convective flows over a bwf step with the aim of investigating the influence of the duct aspect ratio. Numerical data were used for $R e$ ranging between $125 \leq R e \leq 375$ and the aspect ratio ranging between $4 \leq A R \leq 24$ to examine their influence on the skin friction and $N u$. The study showed that a $R e$ of 250 and an aspect ratio of minimum 16 are required to secure the $2 \mathrm{D}$ region in the central part of the duct.

Chen et al. [25] investigated the influence of step height on heat transmission and turbulent separated flow using numerical simulation for the turbulent forced convective flow approach to a $2 \mathrm{D}$ bwf step. The duct's height and $R e$ were kept constant at $H=0.19 \mathrm{~m}$ and $R e=28,000$, respectively while the expansion ratio was kept constant at $E R=1.11,1.24$ and 1.67, respectively. The heat flux is uniform at $q_{w}=270 \mathrm{~W} / \mathrm{m}^{2}$ and the downstream wall from the step fixed whereas the rest of the walls have been arranged as adiabatic. It was found that as the step height increased, the magnitude of the maximum turbulent kinetic energy, primary and secondary recirculation regions and the bulk temperature had also increased. It was observed that the step height had increased and the kinetic energy became smaller below and near the step height. Furthermore, the results showed that the highest temperature increases linearly with the step height. Kherbeet et al. [26] described the heat transfer experiment with consistent temperature of the wall and the outcome of the laminar flow of air that passes through a facing-step channel with backward. It is deduced that the streamwise direction is able to improve the heat transfer under laminar flow when compared with the smooth channel value while establishing the ideal heat transfer gained at the downstream reattachment point.

From the literature, it is clear that the flow over the fwf step has not attained extensive scholarly attention from researchers compared to bwf step case. This is partly due to the several recirculation regions in the fwf step geometry that can develop and make it more intricate to investigate compared with the bwf step geometry, wherein a single recirculation region can be placed behind the step.

\section{Heat transfer with baffles through facing step}

Among many approaches of heat transfer enhancement in cooling systems, some of them would be the baffles, jet impingement and ribs. Various engineering applications have utilized this method such as the gas turbine internal cooling systems of the blades, electronic cooling device, turbomachinery machines, thermal regenerators and shell-and-tube heat exchanger [2]. Habib et al. [27] studied experimentally the flow characteristic and turbulent heat transfer through the periodic cell among segmented baffles staggered in straight channels. The previous researchers have implemented the solid segmented baffles.

From the literatures, there is no study focus on corrugated facing step with baffle, even though many previous researches showed that by instilled baffle in the channel has significant effect on heat transfer enhancement. Heshmati et al. [28] studied the heat transfer through facing step baffle channel. They were utilizing an inclined slotted baffle with nanofluids through backward facing step. Different nanoparticles concentration (0 to $4 \%$ ), Re in the range of 50 to 400 and diameter of 20 to 50 were used. It was found that $\mathrm{SiO}_{2}$ with $20 \mathrm{~nm}$ nanoparticles and $2 \%$ volume fraction has had the greatest performance for heat transfer augmentation. Apart from that, it was observed that the inclined baffle has the highest average $\mathrm{Nu}$ when placed with high skin friction and pressure drop beside the heated wall. Nevertheless, the slotted baffle that inclined at $D=0.5$ with the increment of $R e$ value was seen to have retained a decent average $N u$ and slight charges of skin friction and pressure drop.

\section{Fundamental of nanofluids}

Heat transmission is largely observed in numerous engineering structures for cooling and heating. The proper cooling is fundamental in countless industrial structures including HVAC, nuclear plants, transportation, and energy generation. The improvement in machineries to accomplish anticipated functionality and reduce volume of products show an enhancement in heat loads that may even surpass $25 \mathrm{~kW}$, thus gases and liquids have low thermal performance because of their low thermal conductivity $(k)$. Several scholars attempted to enhance the $k$ of the fluid through suspending micrometer- or millimetre- sized solid particles in liquids. The first attempt to use millimetre-sized particles suspended in water was made by Maxwell [16] but due to high density and large size, the small particles settle out of the suspension.

Since the time that Maxwell detected settlement as a result of particles' density and bulkiness, various researches were conducted to separate solid particles in liquid. Choi [9] proposed the name of nanofluid on 1995 and considered the innovative theory of dispersing nanometer-sized particles in to the base fluid in 1993. Nanofluids have the quality of being very small in size. Such quality allows nanofluids to have less sedimentation, particle erosion, pressure drop, and passage clogging compared with microfluids or 
fluid with large scaled suspensions. From the time when Choi's concept has been presented, the attraction of studying nanofluids have noticeably increased, and numerous studies have been conducted in several facilities and fields to study the functions, applications, structures, environmental impact, mechanisms, and additional features of nanofluids. Several researchers including but not limited to Wen et al. [29], Wang and Mujumdar [30], Yu et al. [29], Wong and Castillo [31], Kakac and Pramuanjaroenkij [32] and Mohammed et al. [2] presented review papers. They stated that nanofluids will create an innovative generation of cooling technology, and this area requires more research to enhance the stability and to prevent cluster phenomena in nanofluids.

\subsection{Nanoparticle material types}

Numerous materials are utilized to make nanoparticles and disperse them in base liquids such as nitride ceramics $(\mathrm{SiN})$, semiconductors $\left(\mathrm{SiO}_{2}, \mathrm{TiO}_{2}\right)$, carbide ceramics $(\mathrm{SiC}, \mathrm{TiC})$, oxide ceramics $\left(\mathrm{CuO}, \mathrm{Al}_{2} \mathrm{O}_{3}\right)$, metals $(\mathrm{Al}, \mathrm{Ag}, \mathrm{Fe}, \mathrm{Cu}, \mathrm{Au})$, single double or multi wall carbon nanotubes (MWCNT, SWCNT, DWCNT) and composites. Furthermore, new structures and materials are preferred to be used in nanofluids whenever the solid- liquid boundary is doped with several molecules. Aerogels are nanoporous light materials consisting of an open-cell network with numerous exceptional characteristics that attract the intuition of scholars in different areas of technology and science. Their range of applications is unlimited, tracking their way in the various fields including thermal and acoustical insulation, and chemistry [33]. Silica aerogel is one of the classes of aerogels, which is porous nanostructure from silica aerogel. It demonstrates very interesting characteristics including low $\mathrm{k}$, low bulk density and optical transparency in the visible spectrum ( 99\%) [33,34]. Such distinctive amalgamation of features is because of the microstructures of Silica aerogel, which consists of nanosized pores. Based on the literature aerogel nanoparticles have not chosen as a candidate to prepared nanofluid to enhance heat transfer.

Nowadays, many researchers work to find new nanofluid for enhance heat transfer, graphene has been used as nanofluid by several researchers [35-37], Ahammed et al. [35] measured the thermal conductivity $k$ of graphene-water nanofluid by means of a transient hot wire technique with different above and below ambient temperatures. The results showed greater $k$ of graphene-water nanofluid as compared with that of the metal oxide nanoparticles, and when compared with that of pure metallic nanoparticles, the same is lower.

\subsection{Preparation of nanofluids}

There are two main methods used to produce nanofluids: single step and double step techniques. Such techniques have been used by employing various kinds of chemical and physical methods to ensure the stability of the solid-liquid mixture in order to prevent agglomeration, additional resistance of flow, probable clogging and erosion, low $\mathrm{k}$ as well as low heat transmission. A double-step process is more reliable for the synthesis of ceramic-based nanofluids. On the contrary, single-step process is perfect for producing metallic nanofluids $[35,38]$.

Single-step method is done by either chemical [39] or physical [40] method. Introduced by Akoh et al. [40], the nanoparticles produced from the direct condensation of metallic vapour involved a contact between the single-step physical synthesis and the low vapour pressure fluid flow [41]. In most base fluid, the single-step method would directly synthesize nanoparticles in it (the base fluid). Therefore, evading the processes of re-dispersion, transportation and drying storage of the metallic nanoparticles [41]. Generally, microwave-assisted route [42], physical vapour deposition [40] and also solution chemical method [39] are implemented for single-step synthesis of nanofluids. The advantage of such methods is minimal agglomeration which escalates the stability of the uniform dispersion and suspensions in the base liquids. Nonethe- less, single-step techniques present a constraint to the amounts of nanofluid production since only low-pressure fluids are presently compatible with these progressions [43].

Double-step methods are also normally used to produce nanofluids. In these methods, the dry nanopowders available from various chemical and physical methods such as mechanical alloying [44], inert gas condensation [38] and physical vapour deposition are dispersed into a base fluid [45]. Nowadays, two-step methods are commonly implemented also due to the fact that it is possible and easy to processes and control the size distribution and the concentration of the solvated nanoparticles [38]. Moreover, the two-step method is more economical process for extensive production of nanofluids as nanopowder production methods have been mounted up to industrial production stages. The drawback of this technique is the greater likelihood of agglomeration of individual particles prior to reaching of complete dispersion because of Van Der Waals attractive forces between nanoparticles [45]. However, to reduce the particles agglomeration Murshed et al. [46] used the ultrasonic equipment to produce $\mathrm{TiO}_{2}$ - water nanofluid. Metallic nanofluids were made by utilizing various double-step methods, yet because of the high agglomeration they did not succeed. Some other techniques have also been utilized to achieve the stability of the nanoparticles in the base liquids employing double-step methods for instance adding surfactants, or controlling PH, and dispersant.

\subsection{Stability}

The most essential issue for increasing the heat transmission is suspension stability in nanofluids. This is generally due to the nanoparticles' tendency to aggregate with the time elapsed for its great surface activity, which leads to the clogging and settlement of channels as well as decreasing the $k$. Nanofluids are expected to remain stable once the concentration of particles is kept steady. Several approaches are utilized to define the stability of nanofluids like absorbency method [47] and sedimentation method $[48,49]$. Sedimentation technique is a highly reliable yet simple technique. It is mostly achieved by specific device that is effective to compute the vibration of particle size or concentration of supernatant particle with sediment time.

\subsection{Applications}

Tzenget al. [50] have studied the effects of nanofluids on the heat transfer across the engine. The nanoparticles of $\mathrm{Al}_{2} \mathrm{O}_{3}$ and $\mathrm{CuO}$ have been applied in the oil of an automatic transmission, and have been tested with an actual engine. Huang and Chein [51] had employed $\mathrm{Cu}$ nanoparticles of different volume fractions to estimate the heat sink microchannel performance. It was found that nanofluid has a significant heat removing influence as compared to pure water with no more penalty of pressure drop due to small diameters and low volume concentration of nanofluids. Hussein $e t$ al. [52] investigated operation competency of operating $\mathrm{SiO}_{2}$ nanofluid in automobile radiator as a coolant fluid. Admirable heat transfer enhancement was included using nanofluid in the automobile radiator. Kleinstreuer and Koo [53] applied nanofluids to eliminate the heat transfer across microwave channel.

\subsection{Viscosity}

Nanofluids are normally utilized under flow conditions and the flow suspension that can be considered largely different from that most mutual heat transmission fluid with Newtonian features. As such, it is highly important to have the rheological characteristics of nanofluids to utilize practically. Rheological features give the information about the microstructure for both dynamic and static situations that are essential for understanding the procedure of heat transmission augmentation by nanofluids. The fluids can be either non-Newtonian or Newtonian, depend on the viscosity. Newton suggested that the share force acting on the liquid is rela- 
tive to the resulting flow velocity. Newtonian fluids called to the fluid which their viscosity remains stable with a rise in share rate. However, when the viscosity varies with a rise in share, it is referred to as non-Newtonian fluid. It is observed that the viscosity of nanofluids is essentially dependent on temperature, volume concentration, and nanoparticles size [54-56]. It is stated that the viscosity decrees with the increase in temperature. Nanofluids with large size nanoparticles and high concentration have high particle interaction and may produce in particle agglomeration and therefore, decrease the heat transfer augmentation and increase the flow resistance. The shape of nanoparticles has an essential part as throughout the share process, particles revolve while they move. Cube-shape particles occupy further volume while revolving compared with spherical particles.

\section{Experimental investigation on nanofluids}

\subsection{Thermal conductivity}

There are numerous experimental works conducted on the $k$ of nanofluids since it is a key valuation of the heat transmission performance. The physical mechanism of the $k$ augmentation of nanofluids needs further studies. Maxwell [57] is known to be a prominent researcher who suspended particles $k$. Through disregarding the connections between the particles they suggested an equation that is merely applicable for mixture with low particle concentrations and employed a really dilute suspension of spherical particles. The gab of particle connections attracts the researcher to improve or extend the Maxwell equation with different factors that influence the $k$ for instance volume concentration [58-60], particle distribution and dispersion [61], particle shape [62], contact resistance $[63,64]$ and particle-shell structure $[65,66]$. Nevertheless, these researches attempted to develop equations to expect $k$. However, the comparison between the theoretical predictions and experimental findings for nanofluids is mostly inadequate. Several new approaches to studying the mechanism were employed to enhance prediction of nanoscale such as nanoparticle cluster [67,68], nanoparticle browning motion [69-71] and also nanoparticle-matrix [72-75].

It is essential to know that the influence of $k$ on nanofluids relies on base fluids, solid particles $k$, shape of particles, thickness and $k$ of nanolayer and volume fraction. Yu et al. [29] presented a comprehensive research of experimental studies on the efficient heat transfer augmentation and $k$ of nanofluid. Wang et al. [76] and Lee et al. [77] illustrated the influence of volume concentration with $23 \mathrm{~nm}$ and $24 \mathrm{~nm} \mathrm{CuO}$ particles in the host fluid of water. It was observed that, by increasing the particles volume concentration the $k$ enhancement increased, $k$ ratio was enhanced by $34 \%$ at $10 \%$ volume fraction. The influence of particle volume fraction with $\mathrm{CuO}$ nanoparticles with ethylene glycol as host fluid has been experimented by Wang et al. [76] and Lee et al. [77]. It was noticed that the volume fraction of $\mathrm{CuO}$ particles with $15 \% \mathrm{k}$ ratio augmented by $50 \%$. Numerous investigations settled on the extent of augmentation with the same test parameters for $\mathrm{CuO}$ in water, $\mathrm{CuO}$ in ethylene glycol $[76,77]$ and $\mathrm{Al}_{2} \mathrm{O}_{3}$ in water $[78,79]$. Figure 4 illustrates that the increasing in volume fraction leads to increase in the heat transmission augmentation. In addition, it is clear that increasing of particle volume concentration encountered with penalty of skin friction and pressure drop coefficient increment [28]. The influence of particles shape on $k$ augmentation in nanofluid is studies by Xie et al. [80]. The results of the study were compared with consider to the geometry shape, base fluid and material. It was observed that outspread particles are better augmentation of the $k$.

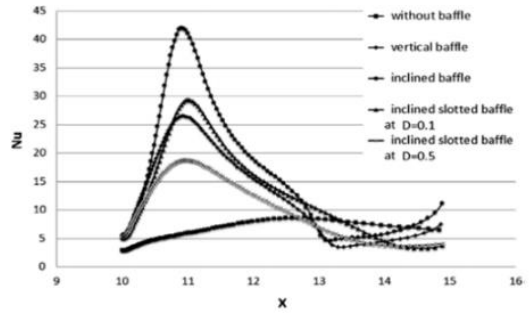

(a)

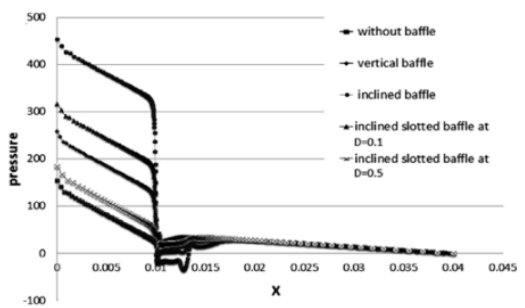

(b)

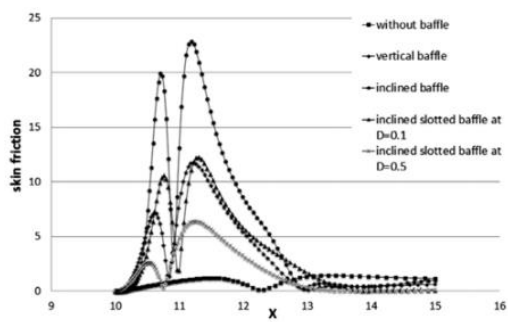

(c)

Fig. 4: (a) Local Nusselt number, (b) pressure drop, (c) Skin friction coefficient, along the heated wall for nanofluid with $\mathrm{dp}=20 \mathrm{~nm}$ and $\mathrm{u}=$ $4 \%$ [28]

The influence of particle size has been examined by Das et al. [78,79], Xie et al. [80,81], Wand et al. [76] with single particlewater combination over a variety of spherical particle diameter from $60 \mathrm{~nm}$ to $20 \mathrm{~nm}$. According to some theories, a uniform distribution of small particles results in higher heat transmission augmentation. On the other hand, it is generally believed that the large particle diameters generate high augmentation in $k$. However the particle size has a significant role in heat transfer and $k$ enhancement in base fluids. The influence of the base fluid material on the $k$ augmentation has been examined by Xie et al. [81]. Enhanced $k$ augmentation of the host fluid that has slight $k$ was observed in the study. These findings are essential for the design of heat exchanger equipment, where heat transmission augmentation is required.

Li and Peterson [82], Wen and Ding [83,84] and Das et al. [85] investigated the influence of temperature on the $k$ augmentation. The findings of their studies show that the $k$ augmentation increases with the increase in temperature. To avoid agglomerating of nanoparticles fluid additives are utilized through the experimentation. Countless studies on work containing additives such as the thioglycolic acid indicate augmentation in $k$ [32]. Various kinds of metallic and non-metallic liquids are utilized as base fluid in order to create nanofluid. Metallic liquids such as Sodium has greater $k$ compared with non-metallic liquids such as organic and water liquids (oil and ethylene glycol). However, water is considered as the best conventional liquid owing to its great $k$ and being friendly to the environment and low cost.

\subsection{The measurement methods of thermal conductivity}

There are several techniques to measure $k$ of nanofluids, such as steady state techniques, transient methods and the thermal comparator method [86]. Transient methods contain thermal constants analyzer [38], transient hot-wire method [46,87], the $3 \omega$ method [88] and temperature oscillation [85]. Cylindrical cell [89] and steady state parallel plate [76] can be instead considered as steady- 
state methods. However, transient hot-wire method is known to be the most implemented solution. Noticeably, Li et al. [90] compared the findings and data from transient and steady state $k$ measurements in $\mathrm{Al}_{2} \mathrm{O}_{3}$ /water nanofluid. According to the findings, both approaches provide similar $k$ rates at room temperature while through raising the temperature, an admirable contradiction between the approaches was obvious. This was because of the onset of natural convection in the hot wire setup [91]. Figure 5 shows the comparison between $k$ measurement methods based on the literature survey.

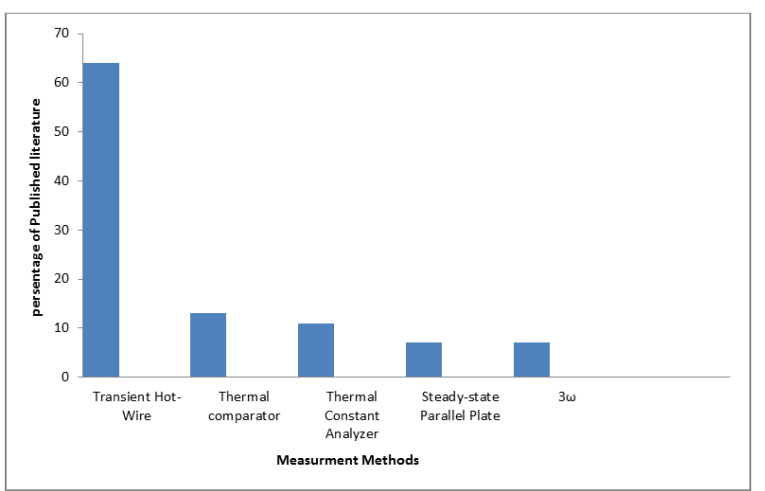

Fig. 5: Comparison of thermal conductivity measurement methods

\section{Nanofluids heat transfer}

Laminar and turbulent flows are some of the two types of flow inside a channel. The experimental findings of the convective heat transfer with the nanofluids showed that it varied with the volume fraction and flow velocity, while being higher than the base fluid under laminar flow conditions as in Table 1 . In addition, various nanoparticle types and concentration levels under several thermal boundary conditions have been examined. This table reports the amount of heat transfer augmentation duo to the use of nanofluids.

Table 1: The laminar forced convection heat transfer enhancement

\begin{tabular}{|c|c|c|c|c|}
\hline Reference & Nanofluid & Type & $\begin{array}{c}\text { Concentration } \\
w t \%\end{array}$ & $\begin{array}{c}\text { Enhancement } \\
\%\end{array}$ \\
\hline $\begin{array}{c}\text { Lion and Liu } \\
{[93]}\end{array}$ & $\begin{array}{l}\text { CNTs } \\
\text { - water }\end{array}$ & $\begin{array}{l}\text { Circular } \\
\text { tube }\end{array}$ & $0.5-2$ & 60 \\
\hline $\begin{array}{c}\text { Chen et al. } \\
\text { [94] }\end{array}$ & $\begin{array}{l}\text { TNT } \\
\text { - water }\end{array}$ & & $0.5-1.5$ & 25 \\
\hline $\begin{array}{c}\text { Hwang et al. } \\
{[95]}\end{array}$ & $\begin{array}{c}\mathrm{Al}_{2} \mathrm{O}_{3} \\
\text { - water }\end{array}$ & $\begin{array}{c}\text { Circular } \\
\text { tube }\end{array}$ & $0.01-0.3$ & 8 \\
\hline He et al. [96] & $\mathrm{TiO}_{2}$ & $\begin{array}{c}\text { Vertical } \\
\text { pipe }\end{array}$ & $0.2-1.2$ & 26 \\
\hline $\begin{array}{c}\text { Bahiraei and } \\
\text { Hangi [7] }\end{array}$ & $\begin{array}{l}\text { Magnetic } \\
\text { /water }\end{array}$ & Annulus & 5 & 18 \\
\hline $\begin{array}{c}\text { Eastman et } \\
\text { al. }[41]\end{array}$ & $\begin{array}{l}\mathrm{CuO} \\
- \text { water }\end{array}$ & $\begin{array}{l}\text { Circular } \\
\text { tube }\end{array}$ & 0.3 & 21 \\
\hline $\begin{array}{c}\text { Chandrasekar } \\
\text { and Suresh } \\
{[97]}\end{array}$ & $\begin{array}{l}\mathrm{Al}_{2} \mathrm{O}_{3} \\
\text { - water }\end{array}$ & $\begin{array}{c}\text { Circular } \\
\text { tube }\end{array}$ & $0.1,0.15,0.2$ & $17,24,34$ \\
\hline $\begin{array}{c}\text { Vajjha and } \\
\text { Das [98] }\end{array}$ & $\begin{array}{c}\mathrm{Al}_{2} \mathrm{O}_{3} \\
\text { - water }\end{array}$ & $\begin{array}{l}\text { Flat } \\
\text { tube }\end{array}$ & 6 & 28 \\
\hline $\begin{array}{c}\text { Abu-Nada } \\
{[99]}\end{array}$ & $\begin{array}{l}\mathrm{CuO} \\
- \text { water }\end{array}$ & $\begin{array}{l}\text { Facing } \\
\text { step }\end{array}$ & 0.2 & 26 \\
\hline
\end{tabular}

Heat transfer coefficient or $\mathrm{Nu}$ signifies the heat transfer of the system and correlation of London and Shah equations were applied under laminar flow condition as [92]:

$N u_{a v}=4.364+0.0722\left(\operatorname{Re}_{D h} \operatorname{Pr} \frac{D h}{L}\right)^{\frac{1}{3}}$

$\left(\operatorname{Re}_{D h} \operatorname{Pr} \frac{D h}{L}\right)<33.33$

$N u_{a v}=1.953\left(\operatorname{Re}_{D h} \operatorname{Pr} \frac{D h}{L}\right)^{\frac{1}{3}}$

$\left(\operatorname{Re}_{D h} \operatorname{Pr} \frac{D h}{L}\right) \geq 33.33$
Under laminar flow conditions, the Darcy correlation of friction factor are used as given by Eqn. 5 .

$f=\frac{64}{R e}$

This equation is used for pure water to validate the simulation results.

According to the findings of their numerical and experimental studies, Kherbeet et al. [92] reveal the heat transfer and flow characteristics of nanofluid laminar flow through microscale backward-facing step. The experiment is conducted at $R e$ range of 280 to 470 with diameter of $30 \mathrm{~nm}$ and two types of nanoparticles $\mathrm{Al}_{2} \mathrm{O}_{3}$ and $\mathrm{SiO}_{2}$. It was noticed that the fraction factor of $\mathrm{Al}_{2} \mathrm{O}_{3} /$ water was greater than $\mathrm{SiO} 2$ / water mixture. Also, it was observed that $N u$ rises with growths in volume fraction. It was deduced that the numerical results conform to the measurement results. Table 2 tabulates the convection heat transfer under turbulent flow within the range of $R e$ up to 4000 of the nanofluid. This table reports the amount of heat transfer augmentation duo to the use of nanofluids types and the volume concentration.

Table 2. The turbulent forced convection heat transfer enhancement

\begin{tabular}{|c|c|c|c|c|}
\hline References & $\begin{array}{c}\text { Nanoflu- } \\
\mathrm{id}\end{array}$ & Type & $\begin{array}{c}\text { Concentra- } \\
\text { tion wt\% }\end{array}$ & $\begin{array}{c}\text { Enhance- } \\
\text { ment } \%\end{array}$ \\
\hline $\begin{array}{c}\text { Pak and Cho } \\
{[100]}\end{array}$ & $\begin{array}{c}\mathrm{Al}_{2} \mathrm{O}_{3} \\
- \text { water } \\
\mathrm{TiO}_{2} \\
- \text { water }\end{array}$ & $\begin{array}{c}\text { Circular } \\
\text { tube }\end{array}$ & $1-3$ & 27 \\
\hline $\begin{array}{c}\text { Vajjha and } \\
\text { Das [98] }\end{array}$ & $\begin{array}{c}\mathrm{Al}_{2} \mathrm{O}_{3} \\
- \text { water }\end{array}$ & Flat tube & 6 & 36 \\
\hline $\begin{array}{c}\text { Togun } \text { et al. } \\
{[101]}\end{array}$ & $\begin{array}{c}\mathrm{Al}_{2} \mathrm{O}_{3} \\
- \text { water } \\
\mathrm{CuO} \\
- \text { water }\end{array}$ & $\begin{array}{c}\text { Facing } \\
\text { step }\end{array}$ & $1-4$ & 37 \\
\hline $\begin{array}{c}\text { Pandey and } \\
\text { Nema [102] }\end{array}$ & $\begin{array}{c}\mathrm{Al}_{2} \mathrm{O}_{3} \\
- \text { water }\end{array}$ & $\begin{array}{c}\text { Corrugat- } \\
\text { ed chan- } \\
\text { nel }\end{array}$ & $2-4$ & 40 \\
\hline $\begin{array}{c}\text { Duangthong- } \\
\text { suk and } \\
\text { Wongwises } \\
{[103]}\end{array}$ & $\begin{array}{c}\mathrm{TiO}_{2} \\
- \text { water }\end{array}$ & $\begin{array}{c}\text { Annulus } \\
\text { [97] }\end{array}$ & $\begin{array}{c}\mathrm{Al}_{2} \mathrm{O}_{3} \\
\text { wand Suresh }\end{array}$ & Circular \\
tube & $0.1,0.15$, & $33,38,51$ \\
\hline $\begin{array}{c}\text { Chandrasekar } \\
\text { water }\end{array}$ & 0.2 & 25 \\
\hline
\end{tabular}

Many researchers use the Dittus-Boelter correlation in Eqn. 6 for pure water.

$N u=0.023 \operatorname{Re}^{0.8} \operatorname{Pr}^{0.4}$

Researchers are adopting this equation to validate the results from an experimental setup before adding nanoparticles. The correlation of fraction factor has been used in many predictions that are accurate and might be determined by Blasius as shown in Eqn. 7 under turbulent low condition .

$f=\frac{0.316}{R e^{0.316}}$

\section{Convective heat transfer of nanofluids}

Convective heat transfer is defined as the phenomenon of macroscopic motion of the fluid relative to the surface due to the heat transfer between them. Two main types of convective heat transfer are forced convective heat transfer where the fluid is forced to flow through a boundary region and natural convective heat transfer where fluid motion is induced by buoyancy. Convective heat transfer of medium depends on its thermo physical properties like thermal expansion coefficient, thermal conductivity, density, viscosity and specific heat capacity. 


\subsection{Forced convection}

Forced convection using nanofluids are very few and they have diverged results from each other. The researcher of forced convective heat transfer using nanofluids observed that there is convective heat augmentation such as Xuan and Roetzel [104], Li and Xuan [105], Jang and Choi [106], Xuan and Li [69], and Lee and Choi [107]. Several studies reported that heat transfer can be enhanced under particular conditions by Lee and Murdawar [108], Chein and Chuang [109], and Pak and Cho [100]. A very limited studies found that decrease in the convective heat transfer coefficient when nanoparticles are added to the base liquids like Yang et al. [110].

\subsection{Natural convection}

The natural convection studies using nanofluids are very limited Even though the research is limited, the available results are diverged. Wen and Ding [111] and Putra et al. [112] made an experimental investigation for natural convective of $\mathrm{TiO}_{2}$ and $\mathrm{Al}_{2} \mathrm{O}_{3}$ nanofluids, respectively. It was observed that the presence of the nanoparticles in water systematically decreased the natural convective heat transfer coefficient. Moreover, it was found that the decrease was due to the influence of sedimentation and particle / fluid slip of nanoparticles. In contrast, Khanafer et al. [113] predicted that nanofluids augment natural convective heat transfer by using numerical technique. However, the natural convictive heat transfer is not well understood, so it requires more research to get a clear view for such phenomena.

\section{Convective of nanofluids in backward and forward facing step channels}

It is observed in the literatures that there are limited numerical and experimental studies done to investigate heat transfer and flow of nanofluids in different geometries with different regimes. Engineering geometry such as annuli and tubes were the first geometry that have been used to investigate nanofluids augmentation. Many studies show that nanofluids have higher thermal transport than any ordinary fluids and their augmentation decreases or increases depending on the change of characteristics and parameter. Some studies have been done to apply nanofluids for systems, microchannels and different geometry shapes. It was noticed that an improvement in thermal transport augmentation.

There are a few papers that investigate the heat transfer and flow effect of nanofluids through bwf step channel. Abu-Nada [99] performed numerically the heat transfer and flow effect through a bwf step using nanofluids. Different types of nanoparticles and volume fraction were used in the based fluid, which was water and flowed through bwf step channel with an expansion ratio $E R=2$. The Prandtl number for the five types of nanofluids was kept constant at 6.2, which are $\mathrm{Al}_{2} \mathrm{O}_{3}, \mathrm{CuO}, \mathrm{TiO}_{2}, \mathrm{AG}$ and $\mathrm{Cu}$. The nanoparticles volume fraction and $R e$ used were in range of $0 \leq \varphi \leq$ 0.2 and $200 \leq R e \leq 600$, respectively. It was found that at the top wall and for $R e=200$, an augmentation in the $N u$ was registered by increasing the volume fraction of the nanoparticles. However, significant enhancement in $\mathrm{Nu}$ was at the top wall for $R e=$ 300 expected in the secondary recirculation zone. The same authors $[114,115]$ investigated numerically the mixed convection assisting flow and the laminar forced through vertical and horizontal bwf step in the channel using nanofluids such as $\mathrm{Au}, \mathrm{Ag}, \mathrm{SiO}_{2}$, $\mathrm{Al}_{2} \mathrm{O}_{3}, \mathrm{Cu}, \mathrm{TiO}_{2}$ and diamond. It was noticed that a primary recirculation section developed downstream of the reattachment point. Also, it was found that low density nanofluids have higher absolute velocity compared to high density nanofluids. Moreover, one minimum and two maximum peaks in $\mathrm{Nu}$ were observed along the heated downstream wall. It is inferred that the diamond nanofluid has the highest minimum peak in the recirculation region while $\mathrm{Au}$ nanofluid has the highest maximum peak of $\mathrm{Nu}$. Moreover, nanofluids with higher $\operatorname{Pr}$ have higher maximum peak of $\mathrm{Nu}$ after the recirculation and separation flow is vanished.

Kherbeet et al. [92] performed a numerical investigation on the laminar mixed convection flow through a 2D horizontal micro scale bwf step MBFS placed in a duct. The straight wall of the duct is maintained at a constant temperature that is higher than the inlet fluids temperature. Different types of nanoparticles such as $\mathrm{SiO}_{2}, \mathrm{CuO}, \mathrm{ZnO}$ and $\mathrm{Al}_{2} \mathrm{O}_{3}$, with volume fractions in range of $1 \%$ to $4 \%$ are used. The step height was $0.96 \mu \mathrm{m}$ and the expansion ratio was 2 . The nanoparticles diameter was in the range of $25 \mathrm{~nm}$ $\leq d_{p} \leq 70 \mathrm{~nm}$. The $R e$ was in the range of $0.05 \leq R e \leq 0.5$. The result showed that the $N u$ increases with increasing volume fraction and $R e$. It is also observed that the $N u$ increase with the decrease of nanoparticle diameter. However, there is no recirculation region was found at the step and along the duct. The same authors also performed a numerical study of heat transfer and nanofluid flow of laminar mixed convection flow over 3D by using horizontal micro scale fwf step channel [116]. The influences of different inclination angle and step height on fluid flow and heat transfer have been discussed. $\mathrm{EG}-\mathrm{SiO}_{2}$ nanofluid is used with $4 \%$ volume fraction and $25 \mathrm{~nm}$ particle diameter. The results show that the $\mathrm{Nu}$ is increased with the step heights increasing. Moreover, the duct inclination angle has no significant effect on the fluid flow and heat transfer rate. There are limited researchers who have used the microscale facing step with mixed convection and most of them showed admirable result in heat transfer enhancement. However, there is no study in this literature that is focused on the natural convection and turbulent flow over microscale facing step using different nanofluids.

\section{Nanofluids in corrugated channels}

There are so limited studies presented in the literature on nanofluids flow in CC and all of them reflected the sinusoidal-corrugated channel. Esmaeili et al. [117] studied the alumina nanofluid in sinusoidal wavy channel. The boundary condition was applied as a constant heat flux on the channel walls. The finite volume method (FVM) was used to solve the governing equations. The results show that, at a given nanoparticle fractions, the $N u$ values at high $R e$ was higher than those at low Re. It was also found that the nanoparticles addition to the base fluid may significantly increase the heat transfer augmentation but the wall share stress will also increase. Heidary and Kermani [118] have performed the heat transfer and laminar flow of nanofluids in sinusoidal-wall channel using finite volume approach. In the simulation, the SIMPLE algorithm was used for the velocity-pressure coupling as well as the collocated grid arrangement has been adopted to store all physical variables. It was found that the heat transfer is enhanced by $50 \%$ with the increasing of nanoparticles volume concentration of cupper as compared to water. Moreover, there was a slight influence of nanoparticles suspension on the skin friction coefficient.

A numerical investigation on the convective heat transfer of nanofluid flow in sinusoidal-wavy channel under constant heat flux has been done by Rostami [119]. The momentum, energy governing equation and continuity were discretized using the finite volume approach and then solve using SIMPLE algorithm. Numerical results were obtained for nanoparticles volume fraction range of 0 to $10 \%$ and $R e$ range of 100 to 250 . The two types of the base fluid such as ethylene glycol and water with $\mathrm{Al}_{2} \mathrm{O}_{3}$ nanoparticles were considered. Friction factor and $\mathrm{Nu}$ increased with the increase of nanoparticles volume and Re. Furthermore, the friction factor and $\mathrm{Nu}$ of $\mathrm{Al}_{2} \mathrm{O}_{3}$ - ethylene glycol nanofluids were higher than those of the $\mathrm{Al}_{2} \mathrm{O}_{3}$ - water nanofluids. The thermal flows of $\mathrm{Al}_{2} \mathrm{O}_{3}$ in eight wave channels have been studied by Ozbolat and Sahin [120]. The amplitude and the wavelength of the wavy channel were 3.5 and $28 \mathrm{~mm}$, respectively. The lower and upper walls of the wavy channel were maintained at uniform wall temperature condition. The numerical data was introduced under 0 to $8 \%$ nanofluid concentrations and $R e$ range of 400 to 1600 . The 
two-dimensional governing equations of momentum, energy and continuity were solved using finite volume approach based on the SIMPLE algorithm. It was found that the heat transfer augmentation increases when the ratio of the channel height decreases. Furthermore, it was noticed that the augmentation in the heat transfer increased with increase in nanoparticles volume fraction and $R e$.

The optimization of particle volume fraction of various nanofluids have been studied by Tiwari [121] based on experimentation in the commercial plate heat exchanger (corrugated channel) for wide range of nanoparticle volume fraction (0 to 3\%). It was found that for maximum augmentation of heat transfer characteristics, different nanofluids work at different optimum volume concentration. For $\mathrm{SiO}_{2} /$ water, $\mathrm{TiO}_{2} /$ water, $\mathrm{CeO}_{2} /$ water and $\mathrm{Al}_{2} \mathrm{O}_{3} /$ water nanofluids, the optimum volume concentration are $1.25 \%, 0.75 \%, 0.75 \%$ and $1 \%$, respectively. At the volume rate of $3 \mathrm{Ipm}$, the corresponding maximum heat transfer augmentations are about $13.9 \%, 24.1 \%$, $35.9 \%$ and $62.35 \%$, respectively. Moreover, it was observed that the optimum concentration for maximum performance index is lower that for maximum heat transfer rate. The influence of nanomaterial in more predominant than that of heat transfer volume flow rate or heat transfer temperature. Furthermore, the optimum concentration depends predominantly on volume flow rate, base fluids, nanoparticle materials and temperature.

Khoshvaght-Aliabadi [122] analyzed by a 2-D numerical simulation the flow characteristics and heat transfer of sinusoidalcorrugated channel with $\mathrm{Al}_{2} \mathrm{O}_{3}$ nanofluid. A parametric study method is used to analyze the performance of sinusoidalcorrugated channel. The influence of channel length, channel height, phase shaft, wave length and wave amplitude at different nanoparticle volume fraction of 0 to $4 \%$ and $R e$ of 6000 to 22000 are evaluated. Darcy friction factor and $N u$ are considered as performance parameters. It is observed that the wave amplitude and channel height have the highest effect on the friction factor and $\mathrm{Nu}$ values. Moreover, the results show that the nanofluid flow inside the sinusoidal-corrugated channels offers higher values of $\mathrm{Nu}$ as compared to the base fluid while the friction factor of both the base fluid and nanofluid are almost the same values. An investigation experiment by the same author [123] to investigate the hydrothermal performance of corrugated/performance fins. The same fluids applied with different considered factors such as waviness aspect ratio, flow rate, concentration and perforation diameter. The result showed that the heat transfer coefficient of CPFs is more than that of typical once while the pressure drop of CPFs is lower. The maximum performance factor of 1.95 is recorded for the CPF with the waviness aspect ratio of 0.51 and perforation diameter of $6 \mathrm{~mm}$ at the flow rate of $0.117 \times 10^{3} \mathrm{~m}^{3} / \mathrm{s}$. Furthermore, higher values of pressure drop and heat transfer coefficient are detected for $\mathrm{Al}_{2} \mathrm{O}_{3} /$ water nanofluids compared with base fluid. Finally, the maximum enhancement of $9.5 \%$ and $14.1 \%$ are detected, respectively, for the pressure drop and heat transfer of 0.3 wt\% nanofluids flow.

\section{Conclusion}

The literature survey shows that nanofluids have significant impact on heat transfer improvement. The understanding of the fundamentals of wall fraction and heat transfer is prime importance for developing nanofluids for a wide range of heat transfer application. However, there are recent developments in the study of heat transfer with nanofluids, more experimental and theoretical studies of the particle movement are needed to understand the fluid flow behaviour and heat transfer of nanofluids. Moreover, in this review paper there are five significant findings as follow:

1. There is no study has focused on convective heat transfer by nanofluid through corrugated facing step. The facing step channels have significant applications for cooling and heating systems in the industrial and engineering field.

2. The comparisons between smooth and corrugated channels show that there was a significant enhancement in heat trans- fer by using corrugated channels. Additionally, the heat transfer has been enhanced by insertion of baffle in channels of a cooling system.

3. Although there are several types of nanoparticle used to prepared nanofluids, Aerogel nanoparticle have never used to prepared nanofluids.

4. There is no previous experimental study discussed the flow and heat transfer over the microscale forward-facing step using different types of nanoparticle. So that, further numerical and experimental works of the flow over microscale backward and forward-facing step is needed.

5. The review also summarized the recent researches of heat transfer enhancement using nanofluids the effect of several parameters such as particle size, particle shape, concentration volume, etc., on enhancing heat transfer were presented.

\section{Acknowledgement}

The author would like to thank the Ministry of Higher Education Malaysia for providing financial support through the Fundamental Research Grant Scheme (FRGS No. TK05/UPM/02/7 Vot. No. 5524896).

\section{References}

[1] Naphon P (2008), Effect of corrugated plates in an in-phase arrangement on the heat transfer and flow developments. Int J Heat Mass Transfer 51, 3963-3971

[2] Mohammed KA, Abu Talib AR, Nuraini AA \& Ahmed KA (2017), Review of forced convection nanofluids through corrugated facing step. Renew Sustain Energy Rev 75, 234-241

[3] Heyhat M, Kowsary F, Rashid A, Esfehani S \& Amrollahi A (2012), Experimental investigation of turbulent flow and convective heat transfer characteristics of alumina water nanofluids in fully developed flow regime. Int Commun Heat Mass Transf 39,1272-1278

[4] Khoshvaght-Aliabadi M, Hormozi F \& Zamzamian A (2014), Role of channel shape on performance of plate-fin heat exchangers: Experimental assessment. Int J Therm Sci 79, 183-193

[5] Tavakoli E \& Hosseini R (2010), Pressure losses and flow patterns in 3D axial flow between corrugated plates. Energy Convers Manag $51,2442-2448$

[6] Heidary H, Abbassi A \& Kermani MJ (2013), Enhanced heat transfer with corrugated flow channel in anode side of direct methanol fuel cells. Energy Convers Manag 75, 748-760

[7] Bahiraei M \& Hangi M (2013), Investigating the efficacy of magnetic nanofluid as a coolant in double-pipe heat exchanger in the presence of magnetic field. Energy Convers Manag 76, 1125-1133

[8] Rush T, Newell T \& Jacobi A (1999), An experimental study of flow and heat transfer in sinusoidal wavy passages. Int J Heat Mass Transf 42, 1541-1553

[9] Fabbri G (2000), Heat transfer optimization in corrugated wall channels. Int J Heat Mass Transfer 43, 4299-4310

[10] Bahaidarah HMS, Anand NK \& Chen HC (2005), Numerical study of heat and momentum transfer in channels with wavy walls. $\mathrm{Nu}$ merical Heat Transfer, Part A : Applications 47(5), 417-439

[11] Wang C \& Chen C (2002), Forced convection in a wavy-wall channel. Int J Heat Mass Transfer 45, 2587-2595

[12] Mohamed N, Khedidja B, Belkacem Z \& Michel D (2007), Numerical study of laminar forced convection in entrance region of a wavy wall channel. Numer Heat Tr A-Appl 53(1), 35-52

[13] Sparrow EM \& Hossfeld LM (1984), Effect of rounding of protruding edges on heat transfer and pressure drop in a duct. Int J Heat Mass Transf 27,1715-1723

[14] Brien J \& Sparrow EM (1982), Corrugated-duct heat transfer, pressure drop and flow visualization. Int J Heat Transf 104, 410-416

[15] Zhang L \& Che D (2011), Influence of corrugation profile on the thermalhydraulic performance of cross-corrugated plates. Numer Heat Tr A-Appl 59(4), 267-296

[16] Li Z \& Gao Y (2017), Numerical study of turbulent flow and heat transfer in cross-corrugated triangular ducts with delta-shaped baffles. Int J Heat Mass Transf 108, 658-670

[17] Oyakawa K, Shinzato T \& Mabuchi I (1989), The effects of the channel width on heat transfer augmentation in a sinusoidal wave channel. JSME International Journal 32(3), 403-410 
[18] Sparrow EM \& Chuck W (1987), Pc solutions for heat transfer and fluid flow downstream of an abrupt, asymmetric enlargement in a channel. Numer Heat Transf 12, 19-40

[19] Aung W (1983), An Experimental Study of Laminar. J Heat Transfer 105(4), 823-829

[20] Iwai H, Nakabe K \& Suzuki K (2000), Flow and heat transfer characteristics of backward-facing step laminar flow in a rectangular duct. Heat Mass Transf 43, 457-471

[21] Nie JH \& Armaly BF (2002), Three-dimensional convective flow adjacent to backward-facing step - effects of step height. Int J Heat Mass Transf 45, 2431-2438

[22] Saldana JGB, Anand NK \& Sarin V (2005), Forced convection over a three-dimensional horizontal backward facing step. Int. J. Comput. Methods Eng. Sci Mech. 6(4), 225-234

[23] Armaly B, Li A \& Nie J (2002), Three-dimensional forced convection flow adjacent to backward-facing step. J Thermophys Heat Transf $16(2), 222-227$

[24] Lan H, Armaly BF \& Drallmeier JA (2009), Three-dimensional simulation of turbulent forced convection in a duct with backwardfacing step. Int J Heat Mass Transf 52, 1690-1700

[25] Chen Y (2006), Turbulent separated convection flow adjacent to backward-facing step effects of step height. Int J Heat Mass Transf 49, 3670-3680

[26] Kherbeet AS, Mohammed HA\& Salman BH (2012), The effect of nanofluids flow on mixed convection heat transfer over microscale backward-facing step. Int J Heat Mass Transf 55, 5870-5881

[27] Habib M \& Mobarak A (1994), Experimental investigation of heat transfer and flow over baffles of different heights. J Heat Transfer $116,363-368$

[28] Heshmati A, Mohammed HA \& Darus AN (2014), Mixed convection heat transfer of nanofluids over backward facing step having a slotted baffle. Appl Math Comput 240, 368-386

[29] Yu W, France DM, Routbort JL \& Choi SUS (2008), Review and comparison of nanofluid thermal conductivity and heat transfer enhancements. Heat Transf Eng 29, 432-460

[30] Wang XQ \& Mujumdar AS (2007), Heat transfer characteristics of nanofluids: a review. Int J Therm Sci 46, 1-19

[31] Wong KV \& Castillo MJ (2010), Heat transfer mechanisms and clustering in nanofluids. Adv Mech Eng 2, 795478

[32] Kakaç S \& Pramuanjaroenkij A (2009), Review of convective heat transfer enhancement with nanofluids. Int J Heat Mass Transfer 52

[33] Bheekhun N, Abu Talib AR \& Hassan MR (2013), Aerogels in aerospace: An overview. Adv Mater Sci Eng 2013, 406065

[34] Pierre AC \& Pajonk GM (2002), Chemistry of aerogels and their applications. Chem Rev 102, 4243-4265

[35] Ahammed N, Asirvatham LG, Titus J, Bose JR \& Wongwises S (2016), Measurement of thermal conductivity of graphene-water nanofluid at below and above ambient temperatures. Int Commun Heat Mass Transf 70, 66-74

[36] Ranjbarzadeh R, Meghdadi Isfahani AH, Afrand M, Karimipour A \& Hojaji M (2017), An experimental study on heat transfer and pressure drop of water/graphene oxide nanofluid in a copper tube under air cross-flow. Appl Therm Eng 125, 69-79

[37] Nazari M, Ghasempour R, Ahmadi M, Heydarian G \& Shafii M (2018), Experimental investigation of graphene oxide nanofluid on heat transfer enhancement of pulsating heat pipe. Int Commun Heat Mass Transf 91, 90-94

[38] Bigdeli MB, Fasano M, Cardellini A, Chiavazzo E \& Asinari P (2016), A review on the heat and mass transfer phenomena in nanofluid coolants with special focus on automotive applications. Renew Sustain Energy Rev 60, 1615-1633

[39] Zhu H, Lin Y \& Yin Y (2004), A novel one-step chemical method for preparation of copper nanofluids. J Colloid Interface Sci 277

[40] Akoh H, Yukihiro Tsukasaki S \& Tasaki A (1978), Magnetic properties of ferromagnetic ultrafine particles prepared by vacuum. J Cryst Growth 45, 495-500

[41] Eastman J, Choi S, Li S, Yu W \& Thompson L (2001), Anomalously increased effective thermal conductivities of ethylene glycolbased nanofluids containing copper nanoparticle. Appl Phys Lett 78

[42] Nikkam N, Ghanbarpour M, Saleemi M, Haghighi E, Khodabandeh R, Muhammed M, Palm B \& Toprak MS (2014), Experimental investigation on thermo-physical properties of copper / diethylene glycol nanofluids fabricated via microwave-assisted route. Appl Therm Eng 65, 158-165

[43] Mahbubul IM, Saidur R \& Amalina MA (2012), Latest developments on the viscosity of nanofluids. Int J Heat Mass Transfer 55

[44] Chopkar M, Das PK \& Manna I (2006), Synthesis and characterization of nanofluid for advanced heat transfer applications. Scr Mater $55,549-552$
[45] Hajipour M \& Molaei Dehkordi A (2014), Mixed-convection flow of A12O3-H2O nanofluid in a channel partially filled with porous metal foam: Experimental and numerical study. Exp Therm Fluid Sci 53, 49-56

[46] Murshed S, Leong K \& Yang C (2005), Enhanced thermal conductivity of TiO2 water based nanofluids. Int J Therm Sci 44, 367-373

[47] Li X, Zhu D \& Wang X (2007), Evaluation on dispersion behavior of aqueous copper nano-suspensions. J Colloid Interface Sci 310

[48] Hwang Y, Lee JK, Lee CH, Jung YM, Cheong SI, Lee CG, Ku BC \& Jang SP (2007), Stability and thermal conductivity characteristics of nanofluids. Thermochimica Acta 455(1-2), 70-74

[49] Hwang Y, Park H, Lee J \& Jung W (2006), Thermal conductivity and lubrication characteristics of nanofluids. Curr Appl Phys 6

[50] Tzeng S, Lin C, Huang KD \& Hua C (2005), Heat transfer enhancement of nanofluids in rotary blade coupling of four-wheeldrive vehicles. Acta Mechanica 23, 11-23

[51] Chein R \& Huang G (2005), Analysis of microchannel heat sink performance using nanofluids. Appl. Therm. Eng. 25, 3104-3114

[52] Hussein AM \& Kadirgama RABK (2014), Heat transfer augmentation of a car radiator using nanofluids. Heat and Mass Transfer 50

[53] Koo J \& Kleinstreuer C (2005), Laminar nanofluid flow in microheat-sinks. Int J Heat Mass Transf 48, 2652-2661

[54] Prasher R, Song D, Wang J \& Phelan P (2006), Measurements of nanofluid viscosity and its implications for thermal applications. Appl Phys Lett 89, 67-70

[55] Chen H, Ding Y, He Y \& Tan C (2007), Rheological behaviour of ethylene glycol based titania nanofluids. Chem Phys Lett 444

[56] Lee J, Hwang K, Jang S, Lee B, Kim J, Choi S \& Choi C (2008), Effective viscosities and thermal conductivities of aqueous nanofluids containing low volume concentrations of $\mathrm{Al} 2 \mathrm{O} 3$ nanoparticles. Int J Heat Mass Transf 51, 2651-2656

[57] Mohammed HA, Al-Aswadi AA, Shuaib NH \& Saidur R (2011), Convective heat transfer and fluid flow study over a step using nanofluids: A review. Renew Sustain Energy Rev 15, 2921-2939

[58] Landauer R (1952), The electrical resistance of binary metallic mixtures. J Appl Phys 23, 779-784

[59] Jeffrey DJ (1973), Conduction through a random suspension of spheres. Proc R Soc A Math Phys Eng Sci 335, 355-367

[60] Davis RH (1986), The effective thermal conductivity of a composite material with spherical inclusions. Int $\mathrm{J}$ Thermophys 7,609 620

[61] Rayleigh L (1892), On the influence of obstacles arranged in rectangular order upon the properties of a medium. London, Edinburgh, Dublin Philos Mag J Sci 5, 481-502

[62] James WB \& Harbor CS (1951), The maxwell-wagner dispersion in a suspension of ellipsoids. J Phys Chem 57, 934-937

[63] Benveniste Y (1987), Effective thermal conductivity of composites with a thermal contact resistance between the constituents: Nondilute case. J. Appl. Phys. 61(8), 2840

[64] Hasselman D \& Johnson L (1987), Effective thermal conductivity of composites with interfacial thermal barrier resistance. J Compos Mater 21, 508-515

[65] Benveniste Y \& Miloh T (1991), On the effective thermal conductivity of coated short-fiber composites. J. Appl. Phys. 69(3), 1337

[66] Lu S \& Song J (1996), Effective conductivity of composites with spherical inclusions: Effect of coating and detachment. J. Appl Phys. 79(2), 609

[67] Wang BX, Zhou LP \& Peng XF (2003), A fractal model for predicting the effective thermal conductivity of liquid with suspension of nanoparticles. Int J Heat Mass Transf 46, 2665-2672

[68] Prasher R, Phelan PE \& Bhattacharya P (2006), Effect of aggregation kinetics on the thermal conductivity of nanoscale colloidal solutions (nanofluid ). Nano Letters 6(7), 1529-1534

[69] Xuan Y \& Li Q (2013), Investigation on convective heat transfer and flow features of nanofluids. J Heat Transfer 125, 151-155

[70] Koo J \& Kleinstreuer C (2004), A new thermal conductivity model for nanofluids. J Nanoparticle Res 6, 577-588

[71] Prasher R, Bhattacharya P \& Phelan P (2005), Thermal conductivity of nanoscale colloidal solutions (nanofluids). Phys. Rev. Lett. 94

[72] Yu W \& Choi SUS (2003), The role of interfacial layers in the enhanced thermal conductivity of nanofluids: A renovated Maxwell model. J Nanoparticle Res 5(1-2), 167-171

[73] Yu W \& Choi SUS (2004), The role of interfacial layers in the enhanced thermal conductivity of nanofluids: A renovated Hamilton - Crosser model. J Nanoparticle Res 6(4), 355-361

[74] Xie H, Fujii M \& Zhang X (2005), Effect of interfacial nanolayer on the effective thermal conductivity of nanoparticle-fluid mixture. Int J Heat Mass Transfer 48, 2926-2932 
[75] Ren Y, Xie H \& Cai A (2005), Effective thermal conductivity of nanofluids containing spherical nanoparticles. J. Phys. D: Appl. Phys. 38(21), 3958

[76] Wang X, Xu X \& Choi S (1999), Thermal conductivity of nanoparticle - fluid mixture. J Thermophys Heat Tr. 13, 474-480

[77] Lee S, Choi S, Li S \& Eastman JA (1999), Measuring thermal conductivity of fluids containing oxide nanoparticles. J Heat Transfer 121(2), 280-289

[78] Das SK, Putra N \& Roetzel W (2003), Pool boiling of nano-fluids on horizontal narrow tubes. Int J Multiph Flow 29, 1237-1247

[79] Das SK, Putra N \& Roetzel W (2003), Pool boiling characteristics of nano-fluids. Int J Heat Mass Transf 46, 851-862

[80] Xie H, Wang J, Xi T \& Liu Y (2002), Thermal conductivity of suspensions containing nanosized $\mathrm{SiC}$ particles. Int $\mathbf{J}$ Thermophys 23, $571-580$

[81] Xie H, Wang J, Xi T, Liu Y, Ai F \& Wu Q (2002), Thermal conductivity enhancement of suspensions containing nanosized alumina particles. J Appl Phys 91, 4568-4572

[82] Li C \& Peterson G (2006), Experimental investigation of temperature and volume fraction variations on the effective thermal conductivity of nanoparticle suspensions (nanofluids). J Appl Phys 99

[83] Wen D \& Ding Y (2004), Experimental investigation into convective heat transfer of nanofluids at the entrance region under laminar flow conditions. Int J Heat Mass Transf 47, 5181-5188

[84] Wen D \& Ding Y (2004), Effective thermal conductivity of aqueous suspensions of carbon nanotubes (carbon nanotube nanofluids). J Thermophys Heat Transf 18, 481-485

[85] Das SK, Putra N, Thiesen P \& Roetzel W (2003), Temperature dependence of thermal conductivity enhancement for nanofluids. J Heat Transfer 125, 567

[86] Paul G, Chopkar M, Manna I \& Das PK (2010), Techniques for measuring the thermal conductivity of nanofluids: A review. Renew Sustain Energy Rev 14, 1913-1924

[87] Garg J, Poudel B, Chiesa M, Gordon JB, Ma JJ, Wang JB, Ren ZF, Kang YT, Ohtani H, Nanda J, McKinley GH \& Chen G (2008), Enhanced thermal conductivity and viscosity of copper nanoparticles in ethylene glycol nanofluid. J Appl Phys 103, 074301

[88] Oh DW, Jain A, Eaton JK, Goodson KE \& Lee JS (2008), Thermal conductivity measurement and sedimentation detection of aluminum oxide nanofluids by using the $3 \omega$ method. Int $J$ Heat Fluid Flow 29, 1456-1461

[89] Kurt H \& Kayfeci M (2009), Prediction of thermal conductivity of ethylene glycol-water solutions by using artificial neural networks. Appl Energy 86, 2244-2248

[90] Li C, Williams W, Buongiorno J, Hu L \& Peterson G (2008), Transient and steady-state experimental comparison study of effective thermal conductivity of Al2O3/water nanofluids.J Heat Transfer 130

[91] Hong SW, Kang YT, Kleinstreuer C \& Koo J (2011), Impact analysis of natural convection on thermal conductivity measurements of nanofluids using the transient hot-wire method. Int $\mathbf{J}$ Heat Mass Transf 54, 3448-3456

[92] Kherbeet AS, Mohammed HA, Salman BH, Ahmed HE \& Alawi OA (2014), Experimental and numerical study of nanofluid flow and heat transfer over microscale backward-facing step. Int J Heat Mass Transf 79, 858-867

[93] Liao L \& Liu ZH (2009), Forced convective flow drag and heat transfer characteristics of carbon nanotube suspensions in a horizontal small tube. Heat Mass Transf 45, 1129-1136

[94] Chen H, Yang W, He Y, Ding Y, Zhang L, Tan C, Lapkin A \& Bavykin D (2008), Heat transfer and flow behaviour of aqueous suspensions of titanate nanotubes (nanofluids). Powder Technol $183,63-72$

[95] Hwang KS, Jang SP \& Choi SUS (2009), Flow and convective heat transfer characteristics of water-based $\mathrm{Al} 2 \mathrm{O} 3$ nanofluids in fully developed laminar flow regime. Int J Heat Mass Transf 52, 193 199

[96] He Y, Jin Y, Chen H, Ding Y, Cang D \& Lu H (2007), Heat transfer and flow behaviour of aqueous suspensions of $\mathrm{TiO} 2$ nanoparticles (nanofluids) flowing upward through a vertical pipe. Int J Heat Mass Transf 50, 2272-2281

[97] Chandrasekar M \& Suresh S (2011), Experiments to explore the mechanisms of heat transfer in nanocrystalline alumina/water nanofluid under laminar and turbulent flow conditions. Exp Heat Transf 24, 234-256

[98] Vajjha R, Das D \& Ray D (2015), Development of new correlations for the Nusselt number and the friction factor under turbulent flow of nanofluids in flat tubes. Int J Heat Mass Transf 80, 353-367
[99] Abu-Nada E (2008), Application of nanofluids for heat transfer enhancement of separated flows encountered in a backward facing step. Int J Heat Fluid Flow 29, 242-249

[100] Pak B \& Cho Y (1998), Hydrodynamic and heat transfer study of dispersed fluids with submicron metallic oxide particles. Exp Heat Transf 11, 151-170

[101] Togun H, Ahmadi G, Abdulrazzaq T, Shkarah A, Kazi SN, Badarudin A \& Safaei MR (2015), Thermal performance of nanofluid in ducts with double forward-facing steps. J Taiwan Inst Chem Eng 47, 28-42

[102] Pandey SD \& Nema VK (2012), Experimental analysis of heat transfer and friction factor of nanofluid as a coolant in a corrugated plate heat exchanger. Exp Therm Fluid Sci 38, 248-256

[103] Duangthongsuk W \& Wongwises S (2010), An experimental study on the heat transfer performance and pressure drop of $\mathrm{TiO} 2$ water nanofluids flowing under a turbulent flow regime. Int J Heat Mass Transf 53, 334-344

[104] Xuan Y \& Roetzel W (2000), Conceptions for heat transfer correlation of nanofluids. Int J Heat Mass Transf 43, 3701-3707

[105] Qiang L \& Yimin X (2002), Convective heat transfer and flow characteristics of $\mathrm{Cu}$-water nanofluid. Science 45, 408-416

[106] Jang SP \& Choi SUS (2006), Cooling performance of a microchannel heat sink with nanofluids. Appl Therm Eng 26, 2457-2463

[107] Lee S \& Choi SUS (1996), Application of metallic nanoparticle suspensions in advanced cooling systems. Am Soc Mech Eng Press Vessel Pip Div PVP 342, 227-234

[108] Lee J \& Mudawar I (2007), Assessment of the effectiveness of nanofluids for single-phase and two-phase heat transfer in microchannels. Int J Heat Mass Transf 50, 452-463

[109] Chein R \& Chuang J (2007), Experimental microchannel heat sink performance studies using nanofluid. Int J Therm Sci 46,57-66

[110] Yang Y, Zhang ZG, Grulke EA, Anderson WB \& Wu G (2005) Heat transfer properties of nanoparticle-in-fluid dispersions (nanofluids) in laminar flow. Int J Heat Mass Transf 48, 1107-1116

[111] Wen D \& Ding Y (2005), Formulation of nanofluids for natural convective heat transfer applications. Int J Heat Fluid Flow 26, 855-864

[112] Putra N, Roetzel W \& Das SK (2003), Natural convection of nano-fluids. Heat Mass Transf 39, 775-784

[113] Khanafer K, Vafai K \& Lightstone M (2003), Buoyancy-driven heat transfer enhancement in a two-dimensional enclosure utilizing nanofluids. Int J Heat Mass Transf 46, 3639-3653

[114] Al-aswadi AA, Mohammed HA, Shuaib NH \& Campo A (2010), Laminar forced convection flow over a backward facing step using nanofluids. Int Commun Heat Mass Transf 37, 950-957

[115] Mohammed HA, Al-Aswadi AA, Abu-Mulaweh HI \& Shuaib NH (2011), Influence of nanofluids on mixed convective heat transfer over a horizontal backward-facing step. Heat Transf - Asian Res 40, 287-307

[116] Kherbeet AS, Mohammed HA, Ahmed HE, Salman BH, Alawi OA, Safaei MR \& Khazaal MT (2016), Mixed convection nanofluid flow over microscale forward-facing step - Effect of inclination and step heights. Int Commun Heat Mass Transf 78, 145-154

[117] Esmaeili M, Sadeghy K \& Moghaddami M (2010), Heat transfer enhancement of wavy channels using $\mathrm{Al} 2 \mathrm{O} 3$ nanoparticles. J Enhanc Heat Transf 17, 139-151

[118] Heidary H \& Kermani MJ (2010), Effect of nano-particles on forced convection in sinusoidal-wall channel. Int Commun Heat Mass Transf 37, 1520-1527

[119] Rostami J (2007), Convective heat transfer in a wavy channel utilizing nanofluids. J Enhanc Heat Transf 14, 333-352

[120] Ozbolat V \& Sahin B (2013), Numerical investigations of heat transfer enhancement of water-based $\mathrm{Al} 2 \mathrm{O} 3$ nanofluids in a sinusoidal-wall channel. ASME International Mechanical Engineering Congress and Exposition

[121] Tiwari AK, Ghosh P \& Sarkar J (2015), Particle concentration levels of various nanofluids in plate heat exchanger for best performance. Int J Heat Mass Transf 89, 1110-1118

[122] Khoshvaght-Aliabadi M (2014), Influence of different design parameters and $\mathrm{Al} 2 \mathrm{O} 3$-water nanofluid flow on heat transfer and flow characteristics of sinusoidal-corrugated channels. Energy Convers Manag 88, 96-105

[123] Khoshvaght-Aliabadi M, Tatari M \& Salami M (2017), Analysis on $\mathrm{Al} 2 \mathrm{O} 3$ /water nanofluid flow in a channel by inserting corrugated/perforated fins for solar heating heat exchangers. Renew Energy $115,1099-1108$ 